\title{
El Ámbito Competencial de la Jurisdicción Indígena Originaria Campesina en materia penal
}

The Scope of Jurisdiction of the Original Indigenous Peasant Jurisdiction in Criminal Matters

A Esfera de Jurisdição da Jurisdição Indígena Camponesa Original em Matéria Penal

Artículo recibido en abril 2021

Arbitraje en mayo 2021

Aceptación en junio 2021

Publicación en julio 2021
Sergio Miranda Hayes

sergiomirandahayes@gmail.com https://orcid.org/ 0000-0002-0554-3042

Universidad Nacional Siglo XX. Llallagua-Bolivia
RESUMEN

ABSTRACT

RESUMO
El presente artículo expone la contradicción existente entre los derechos indígenas originarios campesinos, el carácter plurinacional del Estado Boliviano y lo dispuesto en la Ley de Deslinde Jurisdiccional en lo pertinente a las disposiciones que restringen las competencias de la justicia indígena en lo relativo al ámbito penal, de forma que, sobre la base del antedicho análisis se propone una compatibilización normativa a nivel legal. Se realizó una investigación documental, en donde fueron analizadas las normas establecidas en la Ley de Deslinde Jurisdiccional en la esfera competencial material en el ámbito penal, partiendo de la concepción del Estado Plurinacional y el pluralismo jurídico. Por lo que se comprendió que, por regla general, los delitos señalados en el art. 10.Il inc. a) de la Ley de Deslinde Jurisdiccional, los cuales son apuntados como ilícitos que no puede conocer la jurisdicción indígena originaria campesina, guardan su razón de ubicarse en esa disposición en mérito a una imperiosa necesidad pública.

Palabras clave: Estado Plurinacional; derechos indígenas originarios campesinos; Bolivia

The present article exposes the existing contradiction between the indigenous native peasant rights, the plurinational character of the Bolivian State and the provisions of the Law of Jurisdictional Demarcation regarding the provisions that restrict the competences of the indigenous justice in the criminal field, so that, based on the above mentioned analysis, a normative compatibilization at a legal level is proposed. A documentary research was carried out, where the norms established in the Law of Jurisdictional Demarcation in the material competence sphere in the criminal area were analyzed, starting from the conception of the Plurinational State and the legal pluralism. Therefore, it was understood that, as a general rule, the crimes indicated in art. $10.1 \mathrm{inc}$. a) of the Law of Jurisdictional Demarcation, which are pointed out as crimes that cannot be heard by the indigenous native peasant jurisdiction, keep their reason to be located in that provision in merit of an imperious public necessity.

Key words: Plurinational State; indigenous rights; Bolivia

Este artigo expõe a contradição existente entre os direitos indígenas, o caráter plurinacional do Estado boliviano e as disposições da Leei de Demarcação Jurisdicional em relação às disposições que restringem as competências da justiça indígena na esfera penal, de modo que, com base na análise acima mencionada, é proposta uma compatibilidade normativa a nível jurídico. Foi realizada uma pesquisa documental, na qual foram analisadas as normas estabelecidas na Lei de Demarcação Jurisdicional na esfera material de competência na esfera penal, com base na concepção do Estado Plurinacional e do pluralismo jurídico. Assim, foi entendido que, como regra geral, os crimes indicados no artigo 10.Il, parágrafo a) da Lei de Demarcação Jurisdicional, que são apontados como crimes que não podem ser ouvidos pela jurisdição indígena camponesa nativa, são justificados pela necessidade imperativa do público de ser incluído nesta disposição.

Palabras chave: Estado Plurinacional; direitos indígenas; Bolívia 
A partir de la promulgación de la Constitución Política del Estado actualmente en vigencia, el 7 de febrero de 2009, Bolivia se constituye en un Estado Plurinacional, conforme lo define su artículo 1. A raíz de ello, el mismo texto constitucional y todo el orden jurídico han sido moldeados en consecuencia. De manera que, el carácter de lo plurinacional ha trascendido en el orden jurídico boliviano. Este rasgo de la ingeniería constitucional boliviana no implica únicamente la existencia de varias naciones dentro de un Estado, entendidas como aquellas que tienen continuidad histórica e identidad cultural propia distintiva (Walsh, 2009: p. 49), sino que las mismas han moldeado al propio Estado, y sus cosmovisiones pasaron a formar parte de su orden jurídico y político (Sousa Santos, 2007; p. 36).

Así, se suscitó un reconocimiento más profundo de los derechos de los pueblos indígenas originarios campesinos, en relación al orden constitucional anterior, pues la forma de entender el Estado mutó hacia lo plurinacional. Esto no solo implicó la aceptación de que varias naciones y jurisdicciones coexistían en la sociedad política y jurídicamente organizada, sino que se adoptaron las cosmovisiones de los pueblos indígenas en el orden constitucional boliviano. Tal adopción resultó en cambios en el andamiaje jurídico boliviano, de manera que surgió la necesidad de la promulgación de varias leyes a efectos de cumplir las disposiciones y el nuevo ethos de la norma fundamental.

En ese contexto se producen características relevantes en el ámbito jurisdiccional. Se ahonda en el reconocimiento del pluralismo jurídico, con igualdad jerárquica entre jurisdicciones, fundado en el ejercicio del derecho a la libre determinación de las naciones y pueblos indígena originario campesinos, en el marco de lo dispuesto en el art. 30.4 de la norma fundamental, a partir de que, se traduce el derecho a ejercitar la justicia indígena, en reconocimiento de las costumbres ancestrales de los pueblos, a la luz de lo referido en el art. 30.14 de la CPE.

Entre las leyes promulgadas por mandato constitucional, se puso en vigencia la Ley 073 de Deslinde Jurisdiccional de 29 de diciembre de 2010 (LDJ de ahora en adelante), en la cual se delimitó el ámbito de vigencia de la jurisdicción indígena originaria campesina (JIOC de ahora en adelante). En materia penal, en el marco de lo dispuesto por el art. 10.II inc. a) de dicha Ley, se restringió de manera enérgica el ámbito material de competencia de la JIOC, situación que se fue acrecentando en el desarrollo jurisprudencial constitucional, limitando aún más el ejercicio del derecho a la autodeterminación de los pueblos indígenas originarios campesinos, en un afán de resguardar los preceptos constitucionales y valores ético-morales establecidos. No obstante, no existe un trabajo investigativo que ahonde en los límites al ejercicio de la capacidad punitiva de la JIOC y su relación con el verdadero alcance conforme a la Constitución y al bloque constitucional.

Con relación al ámbito competencial en materia penal de la jurisdicción indígena originaria campesina, dentro del marco del Estado Plurinacional, a partir de la promulgación y puesta 
en vigencia de la Ley de Deslinde Jurisdiccional, surge la necesidad o interrogante ¿Con la promulgación de la Ley de Deslinde Jurisdiccional, se ha restringido el ejercicio de la capacidad punitiva de la Jurisdicción Indígena Originaria Campesina en materia penal, en contra de la concepción del Estado Plurinacional y la visión pluralista de la Constitución Política del Estado?, buscando con ello, el análisis de la concepción del Estado Plurinacional de la Constitución Política del Estado y el reconocimiento de los derechos de los pueblos indígena originario campesinos, entre ellos, el reconocimiento al derecho a ejercer su propia jurisdicción en la resolución de casos en el ámbito penal, derecho que han ejercido ancestralmente, pero que se ha visto restringido con lo dispuesto por el art. 10.II inc. a) de la Ley de Deslinde jurisdiccional, por lo cual, se realiza un estudio de las líneas jurisprudenciales del Tribunal Constitucional Plurinacional sobre el tema.

La incertidumbre en cuanto a los alcances de la competencia de la jurisdicción indígena originaria campesina en el ámbito penal, ha sido el carácter plurinacional del Estado en el marco de lo dispuesto por el art. 1 de la Constitución Política del Estado y el reconocimiento de los valores ético-morales fundamentales a la luz de lo establecido por el art. 9 de la norma fundamental decantan que Bolivia es un país donde el pluralismo jurídico es un eje fundante del orden jurídico y político, donde la jurisdicción indígena originaria tiene igualdad jerárquica que la ordinaria, fundada en el ejercicio del derecho a la libre determinación de las naciones y pueblos indígena originario campesinos, en razón a lo ordenado por el art. 30.II.4 de la norma fundamental. Ello se traduce en el derecho a ejercitar la justicia indígena, en reconocimiento de las costumbres ancestrales de los pueblos, a la luz de lo reconocido en el art. 30.II.14 de la norma básica, y no obstante, aún a pesar de la promulgación de la Ley de Deslinde Jurisdicción, en materia punitiva es difusa la competencia que ejerce la Jurisdicción indígena, toda vez que la Constitución es de aplicación directa 109.I de la norma fundamental y podría entenderse que se pueden aplicar los derechos indígenas señalados en la Constitución incluso sobre la citada ley, lo que, en los hechos, hace difícil delimitar en forma clara y cabal la competencia de la jurisdicción indígena originaria campesina en el ámbito penal.

De todo lo manifestado durante el desarrollo del estudio surgió la formulación de la interrogante de investigación ¿La disposición contenida en el art. 10.II inc. a) de la Ley de Deslinde Jurisdiccional restringe el alcance de la jurisdicción indígena originaria campesina para implementar justicia en materia penal?

A partir de su Preámbulo, la Constitución Política del Estado Boliviano reconoce la naturaleza plural del pueblo boliviano, y en su artículo 1 claramente se identifica a Bolivia como un Estado unitario social de derecho plurinacional y comunitario, reconociendo que se funda en la pluralidad y el pluralismo jurídico, entre otros. Así, en el cuerpo de la Ley Fundamental, se marca fuertemente el contenido pluralista, en especial en lo relativo al reconocimiento de los derechos de los pueblos indígena originarios campesinos, que constituyen parte sustancial de la población, siendo comunidades en las que aplican sus propios sistemas normativos. 
Los diversos instrumentos internacionales relativos al tema -como la Carta de Naciones Unidas, Pacto de Derechos Civiles y Políticos y el Pacto de Derechos Económicos, Sociales y Culturales, por ejemplo-, han establecido que "todos los pueblos del mundo tienen el derecho de libre determinación", de modo que no puede privarse a un pueblo del ejercicio de sus derechos para el desarrollo de su vida pública. Entre tales derechos, se encuentra la facultad de solucionar las controversias que se presentan dentro de la vida en comunidad, como el hecho de dirimir problemas en cuanto a conductas sancionables desde la óptica y concepción de los pueblos indígenas, tanto en la configuración de la acción como en las sanciones a aplicarse.

Efectivamente, desde antes de la colonia y la república, en el espacio geográfico que hoy es Bolivia, los pueblos indígenas han venido aplicado su propio sistema de justicia para la resolución de conflictos y controversias, que subsiste hasta ahora, habiendo sido reconocido constitucionalmente a partir de la reforma de 1994, aunque de manera tibia inicialmente, y de manera más clara en la Constitución Política del Estado vigente desde el 7 de febrero de 2009, que, además de reconocer el pluralismo jurídico en su artículo primero, establece su igualdad jerárquica con la jurisdicción ordinaria.

El art. 109.I de la Constitución Política del Estado (CPE), reconoce el derecho a la libre autodeterminación de los pueblos, en un orden constitucional imbuido por valores ético-morales y principios indígenas originarios campesinos, una caracterización de Estado Plurinacional y la aplicación directa de la Constitución.

Al presente, luego de más de veinte años de la promulgación de la Constitución y a diez años de la Ley de Deslinde Jurisdiccional, no existe un trabajo académico dedicado específicamente a delimitar el alcance material de la JIOC en materia penal, debiendo comprenderse que la asimilación competencial en dicha materia por parte de la jurisdicción ordinaria, resulta en una universalización cultural (Cocarico, 2006, p. 22), contraria a lo dispuesto por el art. 1 de la norma fundamental y a toda la concepción plurinacional y pluralista que tiene la misma. Por ello, sobre la base de lo dispuesto en la Constitución Política del Estado, se realiza la presente investigación que indudablemente refleja aportes en lo teórico, práctico y científico, conforme se explica a continuación.

A efectos de lograr el objetivo general, se realiza un análisis doctrinal sobre las posturas de diversos juristas que han abordado la temática del pluralismo jurídico y los derechos de los pueblos indígenas, entre ellos el derecho a su propia jurisdicción; asimismo, se indagará sobre la concepción de la visión de país que se tuvo a momento de elaborar y redactar la actual Constitución Política del Estado, estableciendo que Bolivia es un Estado Plurinacional y que se asienta, entre otros, en el pluralismo jurídico, de manera que se contribuirá al estudio del tema desde el punto de vista doctrinal.

De conformidad a lo establecido por su art. 410, la Constitución Política del Estado es la Ley Suprema del ordenamiento jurídico boliviano, de manera que toda disposición infra constitucional debe estar de acuerdo a los principios, valores y preceptos constitucionales, 
así como a la concepción y espíritu de la Ley Fundamental, en virtud de lo cual, al realizar el estudio de lo dispuesto por la Ley de Deslinde Jurisdiccional en cuanto a la potestad sancionatoria en materia penal de los pueblos indígenas y el desarrollo jurisprudencial del Tribunal Constitucional Plurinacional al respecto, y plantear una modificación de la mencionada Ley, se estará efectuando un aporte práctico que bien podría ser considerado por la instancia pertinente -Asamblea Legislativa Plurinacional-, con el fin de armonizar dicho instrumento legal con lo dispuesto por la Ley Suprema del país, tomando en cuenta el derecho a ejercer sus normas ancestrales por parte de los PIOC, dentro de los límites que la propia Constitución determina, pero que la Ley ha ampliado demasiado, restringiendo en sumo grado la potestad punitiva de dichos pueblos.

El pluralismo jurídico está siendo analizado hace algunos años por diversidad de doctrinarios y juristas, cuyos aportes serán estudiados en la presente investigación y sobre cuya base el autor efectuará su propuesta, sustentada desde el punto de vista teórico, científico, jurídico constitucional y práctico, de modo que al concluir el trabajo podrá efectuar un aporte sobre la temática del ejercicio de los derechos de los pueblos indígenas y en especial sobre el derecho a ejercer su propia jurisdicción en la resolución de conflictos de tipo penal, siempre considerando las limitaciones que la Ley Fundamental ha establecido.

\section{Ajustada al derecho}

METODOLOGÍA

Se llevó a cabo una sistematización de los principales fundamentos normativos y doctrinales sobre el ejercicio de las competencias en materia penal de la JIOC; seguidamente se realizó la estructuración del conocimientos en materia de derechos indígenas en Bolivia, en relación al ejercicio de su competencia jurisdiccional en materia penal, por último se realizó un diseñó sobre la base de un entendimiento jurisprudencial óptimo para el ejercicio óptimo de derechos indígenas en relación al ejercicio de su competencia en materia penal. Bajo el campo de acción Normativa constitucional y legal en relación al ejercicio de la competencia en materia penal de la Jurisdicción Indígena Originaria en Bolivia.

Se realizó una investigación documental, en donde fueron analizadas las normas establecidas en la Ley de Deslinde Jurisdiccional en la esfera competencial material en el ámbito penal, partiendo de la concepción del Estado Plurinacional y el pluralismo jurídico. Fue explicativa porque se identificaron los aspectos que, a partir de la visión plurinacional del Estado boliviano, tendría que contemplar la Ley de Deslinde Jurisdiccional en cuanto a la competencia material de los pueblos indígena originarios campesinos en el ejercicio de su jurisdicción. Fue propositiva porque, sobre la base de la concepción del Estado plurinacional y del pluralismo, así como del estudio jurisprudencial, se propone una modificación de la Ley 073.

Los métodos usados fueron método bibliográfico mediante cual se realizó la revisión y análisis de medios tanto físicos como digitales, relativos al objeto de estudio. El Método de Análisis y 
Síntesis Utilizado para la puntualización objetiva de conceptos y conocimientos. Y el Método Histórico - Lógico. - Con el cual se abordó la evolución respecto al eje temático.

La variable independiente desarrollada en el estudio estuvo relacionada con la normativa sobre derechos indígenas originarios en el orden constitucional boliviano, y la variable dependiente es acerca de la Restricción de los derechos indígenas y el pluralismo jurídico. (Tabla 1).

Tabla 1. Variables (operacionalización).

\begin{tabular}{|c|c|c|c|c|}
\hline Variable & $\begin{array}{l}\text { Definición } \\
\text { conceptual }\end{array}$ & $\begin{array}{l}\text { Definición } \\
\text { Operacional }\end{array}$ & Dimensiones & Indicadores \\
\hline $\begin{array}{l}\text { Los derechos } \\
\text { indígenas y el } \\
\text { pluralismo jurídico } \\
\text { en el orden } \\
\text { constitucional } \\
\text { boliviano } \\
\text { V.I }\end{array}$ & $\begin{array}{l}\text { El conjunto de } \\
\text { atributos de los } \\
\text { pueblos originario } \\
\text { campesinos que } \\
\text { permite a este } \\
\text { sector impartir } \\
\text { justicia dentro de } \\
\text { su jurisdicción en } \\
\text { el marco de lo } \\
\text { dispuesto en el } \\
\text { Art. } 10.1 \text { inc. a) de } \\
\text { la Ley de Deslinde } \\
\text { Jurisdiccional. }\end{array}$ & $\begin{array}{l}\text { Ámbito de vigencia } \\
\text { de la competencia } \\
\text { de la jurisdicción } \\
\text { indígena }\end{array}$ & Normativa legal & $\begin{array}{l}\text { Enumeración de } \\
\text { delitos que puede } \\
\text { resolverse en la } \\
\text { JIOC } \\
\text { Relación de } \\
\text { derechos } \\
\text { constitucionales } \\
\text { y disposiciones } \\
\text { legales } \\
\text { Jurisprudencia sobre } \\
\text { los límites de la } \\
\text { JIOC } \\
\text { Enumeración de } \\
\text { delitos que puede } \\
\text { resolverse en la } \\
\text { JIOC }\end{array}$ \\
\hline $\begin{array}{l}\text { Restricción de los } \\
\text { derechos indígenas } \\
\text { y el pluralismo } \\
\text { jurídico } \\
\text { V.D. }\end{array}$ & $\begin{array}{l}\text { Límites impuestos } \\
\text { a los derechos } \\
\text { indígenas y el } \\
\text { ejercicio del } \\
\text { pluralismo } \\
\text { jurídico para que } \\
\text { la jurisdicción } \\
\text { originaria ejerza su } \\
\text { competencia. }\end{array}$ & $\begin{array}{l}\text { Ámbito de la } \\
\text { atribución, en una } \\
\text { interpretación } \\
\text { extensiva de } \\
\text { derechos indígenas } \\
\text { originarios } \\
\text { campesinos, en } \\
\text { aplicación directa } \\
\text { de la constitución, } \\
\text { que tiene la } \\
\text { jurisdicción para } \\
\text { administrar justicia. }\end{array}$ & $\begin{array}{l}\text { Normativa } \\
\text { constitucional } \\
\text { Tratados } \\
\text { internacionales en } \\
\text { materia de derechos } \\
\text { indígenas. }\end{array}$ & $\begin{array}{l}\text { Enumeración de } \\
\text { delitos que deberían } \\
\text { resolverse en la } \\
\text { JIOC } \\
\text { Relación de } \\
\text { derechos } \\
\text { constitucionales } \\
\text { y disposiciones } \\
\text { legales } \\
\text { Jurisprudencia sobre } \\
\text { el ámbito de validez } \\
\text { de la competencia } \\
\text { en materia penal de } \\
\text { la JIOC }\end{array}$ \\
\hline
\end{tabular}




\section{RESULTADOS Y DISCUSIÓN}

Después de realizado el estudio teórico, conceptual y contextual, fue necesario presentar los datos e información obtenida, respeto al desarrollo normativo, teórico y jurisprudencial en uso de los métodos planteados para el cumplimiento del objetivo de proponer cambios a la normativa legal vigente en cuanto a la competencia de la jurisdicción indígena en materia penal. En ese mérito, se expone a continuación los hallazgos del estudio.

\section{Presentación e interpretación de resultados}

La composición de la población plural de Bolivia ha generado repercusiones en el orden jurídico de este país. Aún a pesar del devenir del tiempo y las distintas fases históricas, con distintos fenómenos sociales que ha atravesado Bolivia, se han mantenido prácticas consuetudinarias para que las comunidades indígenas impartan justicia. No obstante, luego de la independencia boliviana no se han reconocido plenamente los derechos de los pueblos indígenas a favor del reconocimiento de un país plural. A principios de los años noventa se han suscrito importantes instrumentos internacionales a favor del reconocimiento de los pueblos indígenas y tribales. Estas circunstancias, han sido el preludio para un más profundo reconocimiento y consideración en la actual Constitución, que se encuentra vigente desde el 2009.

El Estado Plurinacional que se ha instituido con la nueva Constitución, ha generado muchos elementos importantes en el entendimiento estatal y jurídico. En ese sentido, se comprende que el Estado es de composición plural, y esta pluralidad es el eje motor del régimen jurídicoestatal, que imbuye el espíritu constitucional. Tal reconocimiento implica la existencia de varias naciones dentro de un mismo país, cuyos valores y principios forman parte del orden constitucional, siendo que, en razón a encontrarse Bolivia en un modelo de Estado Constitucional de Derecho Plurinacional, conforme a lo dispuesto en el art. 1 de la norma fundamental.

Desde la vigencia del Estado Plurinacional, se generan varios elementos que deben tomarse en cuenta. En primer lugar, resulta en la potenciación de cada uno de los derechos de los pueblos indígenas. En segundo, que los principios y valores de las naciones indígenas originaria campesinas formen parte del orden constitucional. Y tercero, que el pluralismo sea un eje motor del nuevo entendimiento jurídico-estatal.

Dentro de los derechos de los pueblos indígena originario campesinos en el régimen constitucional boliviano, se encuentra el derecho a la libre determinación, en concordancia con lo dispuesto en el art. 2 de la norma fundamental. En ese orden, se señala, en el mismo cuerpo jurídico constitucional en su art. 190.l, que las naciones y pueblos indígenas originario campesinos ejercerán sus funciones y competencias mediante sus autoridades, aplicando sus principios, valores, normas y costumbres. 
Empero, la puesta en vigencia de la Ley 073 de 16 de diciembre de 2010, Ley de Deslinde Jurisdiccional, ha generado algunas contradicciones en el orden jurídico boliviano. Este cuerpo legal, delimita el ejercicio de la jurisdicción indígena originaria campesina a través de sus arts. $7,8,9,10$ y 11 . Identificando los ámbitos de vigencia personal, territorial y material. En ese mérito, se expuso que, en razón a lo dispuesto en el art. 9 de la citada ley, se entiende que la competencia de la JIOC se aplica únicamente a miembros de la comunidad, empero el criterio de pertenencia a una nación o pueblo indígena originario campesino no se funda únicamente en el nacimiento o rasgos físicos de algún grupo étnico sino que la identidad cultural, idioma, integración en la organización administrativa, territorial, ritualidad y cosmovisión, son parámetros que harán de una persona parte de estos sectores de la población y por lo tanto, los convertirá en merecedores de los derechos y podrán someterse a su jurisdicción.

Asimismo, dentro del ámbito de vigencia territorial, se ha mencionado que éste se aplica a los territorios de las jurisdicciones indígena originaria campesina en concordancia con lo dispuesto en el art. 11 de la Ley de Deslinde Jurisdiccional, empero conforme a lo desarrollado por la SCP 0026/2013 de 4 de enero, se comprende que cuando existan hechos que se produzcan fuera del indicado territorio pero tenga efectos en la cohesión social colectiva de la comunidad, éstos serán de competencia de la JIOC, resultando en entendido como extraterritorialidad jurisdiccional.

Respecto al ámbito material de vigencia de la JIOC, se ha identificado que éste restringe el carácter plurinacional del Estado respecto al ejercicio del derecho a libre determinación de los pueblos indígenas originario campesinos. En ese sentido, se advirtió que el art. 10 de la citada ley, enumera una lista ampulosa de materias que no puede conocerse en la justicia indígena, esto implica que de manera residual el resto de las materias que no se encuentran indicadas en dicha disposición legal, pueden ser tramitadas ante la jurisdicción indígena.

Ello contradice los principios plurales que erigen el Estado Constitucional Plurinacional de Derecho, considerando que existe una vocación anticolonial de recuperación, reconocimiento y resguardo de los principios y valores indígenas, tomando en cuenta también la igualdad de jurisdicciones que reconoce el art. 30.II.4 en concordancia con lo dispuesto en el art. 179.II de la norma fundamental. En ese contexto, se considera que la Ley de Deslinde Jurisdiccional no haya una compatibilidad plena con la Constitución Política del Estado.

En ese mérito, se realizó un análisis de proporcionalidad, el cual se aplica en varios tribunales constitucionales en el mundo y en la corte constitucional boliviana, método extraído de la teoría de Robert Alexy (2008) quien identificó tres fases del test respectivo. Para tal fin se analizó, en base al test de proporcionalidad el art. 10.II inc. a) de la Ley de Deslinde jurisdiccional a todos y cada uno de los delitos enlistados en esta disposición legal.

Por lo que se analizó si la medida limitativa o restrictiva es idónea, si ésta es necesaria y, por último, si es estrictamente proporcional. De este test se identificó que los delitos en materia de corrupción cuando generen efectos en la comunidad o nación, a efectos de una compatibilización 
constitucional, deben poder se tramitados ante la jurisdicción indígena originaria campesina, siendo que, del análisis empleado, se comprende que los delitos contra el derecho internacional, delitos por crímenes de lesa humanidad, delitos contra la seguridad interna y externa del Estado, terrorismo, delitos tributarios y aduaneros, tráfico de armas, narcotráfico, delitos cometidos en contra de la integridad corporal de niños, niñas y adolescentes, violación, trata y tráfico de personas, asesinato y homicidio, obedecen a una noción de imperiosa necesidad social, parámetro establecido por la Corte Interamericana de Derechos Humanos, a través de la Opinión Consultiva 5/85 de noviembre de 1985, que se constituye en un requisito para cualquier restricción que exista a derechos fundamentales, que en el caso que ocupa el presente análisis, es el derecho a la libre determinación.

Asimismo, se advirtió una noción jurisprudencial importante, la cual ha sido instituida por el Tribunal Constitucional Plurinacional, máximo intérprete de la Constitución, el cual ha identificado mediante la SCP 0037/2013 de 4 de enero que, la distinción material como ámbito competencial señalada en la Ley de Deslinde Jurisdiccional, a través de su art. 10, no rige en la mayoría de los casos en los pueblos indígena originario campesinos. De forma que, desde una interpretación amplia, sistémica y teleológica de los principios y derechos establecidos en la CPE, el ámbito competencial material de la JIOC es aquel que tradicionalmente ha tenido para conocer y resolver hechos y asunto, independientemente de su gradualidad, es decir, si se consideran leves, graves, penales o civiles.

Este elemento aporta enérgicamente a comprender la circunstancia jurídica del objeto de estudio, pues a través de esta noción y de la aplicación del test de proporcionalidad, se identifica una carencia de compatibilidad entre el carácter plurinacional-constitucional del Estado con el art. 10.11 inc. a) de la Ley de Deslinde Jurisdiccional, de forma que a través de la identificación de estos extremos se genera una propuesta que genere lo necesario para una armonía normativa en el régimen jurídico boliviano, conforme se evidencia más adelante.

\section{Análisis y diagnóstico}

El Estado Plurinacional es un paradigma jurídico-político que enarbola el carácter plural, conjuntamente con todas sus implicancias. La plurinacionalidad es un eje fundacional del Estado boliviano, esta forma de comprensión estatal, es un principio y valor, que alberga en sí un contenido ideológico de vocación anticolonialista, en mérito a lo estudiado en la SCP 1714/2012 de 1 de octubre, pues se constitucionalizan nuevos principios y valores supremos de carácter plural, que tienen origen en la cosmovisión de los pueblos indígena originario campesinos.

De esta forma, mediante la puesta en vigencia de la CPE de 2009, se efectúa una transformación de república a un estado plurinacional, que se erige bajo el tenor de la búsqueda de una descolonización ideológica, política, económica y social, fundada en el carácter plural del 
Estado preservando su unidad. El carácter plural del país, expresado en el pluralismo jurídico, piedra angular en temas de justicia y reconocimiento de derechos, debía ser punta de lanza para el direccionamiento de toda la producción normativa del país. No obstante, en la Ley 073 de 16 de diciembre de 2010, Ley de Deslinde Jurisdiccional, se advierte que no existe una compatibilización entre el reconocimiento pleno del pluralismo jurídico y el orden legal del país. En ese sentido, esta ley, resquebrajó lo establecido en el art. 179.II de la CPE, pues si bien esta disposición constitucional reconoce la igualdad jerárquica entre la jurisdicción ordinaria y la jurisdicción indígena originaria campesina, desde la puesta en vigencia de la Ley de Deslinde Jurisdiccional, este mandato constitucional es incumplido.

Esto sucede porque la columna vertebral de la citada ley, que es su art. 10, cercena diversas materias del conocimiento de la competencia de la JIOC. Esto sucede incluso en el ámbito penal, en mérito a lo dispuesto en el art. 10.Il inc. a) de la Ley de Deslinde Jurisdiccional, pues se expone que delitos no pueden ser de conocimiento de dicha jurisdicción, abriendo únicamente la posibilidad de que aquellos más leves sean tratados ante la JIOC.

Al ejercitar una medida de control de constitucionalidad del art. 10.Il inc. a) de la Ley de Deslinde Jurisdiccional, mediante el test de proporcionalidad, se han identificado elementos jurídicos muy importantes que surgen a partir del principio de primacía constitucional y la ponderación entre una norma legal con el conjunto de principios y disposiciones constitucionales. En ese mérito, se pasa por las fases del test de proporcionalidad. Las cuales son, la idoneidad, necesidad y proporcionalidad estricta.

De lo analizado en cuando al test de idoneidad, que implica que las medidas restrictivas impuestas en el art. 10.II inc. a) de la Ley de Deslinde Jurisdiccional, sean aptas para el fin que persigue la naturaleza de la disposición. Al respecto, se identificó que la limitación a la competencia material penal de la JIOC en dicho mandato legal, es idóneo para el fin perseguido que se interpreta que es la regulación de los límites entre jurisdicciones.

Asimismo, respecto al análisis de necesidad, el cual implica que la limitación a los derechos a los preceptos constitucionales sea necesaria y no exista otra menos restrictiva, se halló, que los delitos contra el derecho internacional, delitos por crímenes de lesa humanidad, delitos contra la seguridad interna y externa del Estado, terrorismo, delitos tributarios y aduaneros, tráfico de armas, narcotráfico, delitos cometidos en contra de la integridad corporal de niños, niñas y adolescentes, violación, trata y tráfico de personas, asesinato y homicidio, deben ser, en virtud a un imperioso interés público, conocidos únicamente por la jurisdicción ordinaria, siendo que los delitos en materia de corrupción cuando tienen efectos dentro de la jurisdicción indígena originaria campesina, respetando su ámbito de vigencia territorial y personal, deben ser tramitados ante esta justicia.

Y por último, en lo que respecta a la última fase del test de proporcionalidad, se halló que al haber concurrido una imperiosa necesidad social, en razón a lo comprendido por la Corte Interamericana de Derechos Humanos a través de la Opinión Consultiva 85/89, de los delitos 
descritos, por su complejidad, interés público, extrema gravedad al identificar delitos contra niños, niñas adolescentes, crímenes de sangre y delitos sexuales, así como contra el orden y el Estado, es que tuvo por aprobado este nivel del examen de proporcionalidad.

No obstante a lo identificado hasta este punto, a través de la SCP 0026/2013 de 4 de enero, se tiene que lo establecido en el art. 10 de la Ley de Deslinde Jurisdiccional no condice con los postulados fundamentales de la constitución boliviana y tampoco obedece a la realidad de la práctica de impartición de justicia de la JIOC. Esto genera que, en función a una interpretación amplia y aplicación directa de la Constitución, en virtud al imperio de los preceptos y principios constitucionales plurales, se tenga que no únicamente la JIOC podrá resolver las materias y delitos no consignados en el art. 10 de la Ley de Deslinde Jurisdiccional, sino también todos aquellos asuntos que hayan sido tradicionalmente conocidos por su organización social acorde a su cosmovisión, cultura, tradiciones, valores principios y normas consuetudinarias. En caso contrario, se advertiría una conculcación al derecho a la libre determinación, que ha sido instituida a través de los tratados internacionales reconocidos en el bloque de constitucionalidad y actualmente homologados en la constitución boliviana.

Estos extremos son los hallazgos del presente trabajo investigativo, el cual se sintetiza en la compatibilización de los preceptos constitucionales, valores, principios y derechos fundamentales de los pueblos indígena originario campesinos con el art. 10.II inc. a) de la Ley de Deslinde Jurisdiccional, a efectos de que esta disposición legal no transgreda la naturaleza misma del Estado Plurinacional, en un reconocimiento pleno de los derechos de este sector de la población y en concordancia con las directrices constitucionales anticolonialistas.

\section{Análisis final}

Las implicancias del Estado Plurinacional trascienden a toda normativa, pues se consolida desde el nivel constitucional, a favor del carácter plural del Estado, el cual debe imbuir toda esfera jurídica, incluyendo las leyes, y con mayor razón, a la Ley de Deslinde Jurisdiccional que delimita las competencias entre las jurisdicciones instituidas en el país.

La noción constitucional en el Estado Plurinacional, paradigma estatal de composición plural, implica que las naciones y pueblos indígena originario campesinos ejerzan funciones y competencias a través de sus autoridades, aplicando e impartiendo justicia conforme a sus valores, normas y procedimientos propios, cosmovisión que a su vez forma parte del modelo de Estado y que funciona como parámetro de interpretación de derechos y comprensión de la organización del poder estatal.

Si bien la justicia indígena se encuentra en la equivalencia jerárquica con la jurisdicción ordinaria y que la jurisdicción indígena es autónoma y tiene una relación de coordinación con las demás jurisdicciones, pero no de sujeción, ésta debe siempre debe limitarse al control constitucional, donde la Constitución Política del Estado, es la que debe gobernar las decisiones jurisdiccionales de los pueblos indígena originario campesinos. 
El margen de ejercicio de la justicia indígena debe ser amplio, en concordancia con los principios y valores estatales, en concordancia con el carácter plurinacional del Estado, situación que debe extenderse a toda normativa.

Si bien la Ley 073 de 16 de diciembre de 2010, Ley de Deslinde Jurisdiccional, persigue la finalidad de delimitar las competencias interjurisdiccionales, debe regirse por los principios y valores del Estado Plurinacional.

La jurisprudencia constitucional, por medio de la labor interpretativa del Tribunal Constitucional Plurinacional ha ahondando en el entendimiento de los ámbitos de vigencia material, personal y territorial de la jurisdicción indígena originaria campesina, aplicando directamente la norma fundamental, flexibilizando los parámetros descritos en la Ley de Deslinde Jurisdiccional.

En el ámbito personal, se comprende que toda persona que se identifique con el pueblo o nación indígena originaria campesina y forma parte de su estructura organizacional, en concordancia con su cosmovisión, puede ser miembro de la comunidad, y por lo tanto, poder someterse a la jurisdicción indígena originaria campesina, no existiendo requisitos de nacimiento o de cualquier otra índole para ello.

En el ámbito territorial se tiene que no únicamente los sucesos que ocurran dentro de la jurisdicción indígena originario campesina serán de tratamiento de ella, sino que también aquellos que pasen fuera de ella pero que tengan efectos en la cohesión social de la comunidad, podrán ser resueltos bajo su competencia.

En el ámbito material, conforme se anotó, existe un cercenamiento a la competencia de la jurisdicción indígena originaria campesina, el art. 10 enfáticamente limita el derecho a la libre determinación, derecho reconocido en los muchos instrumentos internacionales que ha ratificado Bolivia y en manera más contundente reconocido en la Constitución, en concordancia con los principios y valores del Estado Plurinacional.

Los instrumentos internacionales en materia de Derechos Humanos de los pueblos indígenas reconoces el derecho a la libre determinación como la potestad a que estos sectores de la población puedan decidir sobre los asuntos que les conciernen, esto implica también el derecho a que puedan ejercitar su justicia conforme a sus procedimientos propios.

Para resolver la tensión existente entre el carácter plurinacional del Estado boliviano, los derechos de los pueblos indígenas y la Ley de Deslinde Jurisdiccional, la cual en su art. 10.II inc. a) limita las facultades de dicho sector para procesar y castigar delitos dentro de las comunidades originarias, debe ejercitarse un control de constitucionalidad sobre esta disposición legal, utilizando, como técnica interpretativa, una que sea aceptada ampliamente en las cortes constitucionales, así como en la doctrina constitucional. 
El test o examen de proporcionalidad es un parámetro casi universal para resolver conflictos jurídicos donde haya normas que se encuentren limitando principios y reglas constitucionales, y en ellas, se ubiquen derechos fundamentales, de forma que se debe usar este test para determinar la compatibilidad constitucional del art. 10.11 inc. a) de la Ley de Deslinde Jurisdiccional.

Las fases del examen de proporcionalidades identificadas por la doctrina constitucional mediante su máximo exponente, Robert Alexy, son la regla de la idoneidad, necesidad y proporcionalidad estricta, aplicadas a ( art. 10.II inc. a) de la Ley de Deslinde Jurisdiccional, decantan en una incompatibilidad de los delitos de corrupción, los que, en conformidad con la regla de necesidad que implica que la medida limitativa sea necesaria y que no exista una menos restrictiva para perseguir el fin de la intromisión constitucional, podrían ser resueltos en la jurisdicción indígena originaria campesina cuando sus efectos generen implicancias en la comunidad, respetando los otros ámbitos de vigencia concernientes.

Se comprendió que, por regla general, los delitos señalados en el art. 10.II inc. a) de la Ley de Deslinde Jurisdiccional, los cuales son apuntados como ilícitos que no puede conocer la jurisdicción indígena originaria campesina, guardan su razón de ubicarse en esa disposición en mérito a una imperiosa necesidad pública, la cual en concordancia con la Opinión Consultiva 5/85 de noviembre de 1985 se constituye en un requisito que debe tener una medida limitativa de derechos y preceptos constitucionales.

No obstante de aquello, la jurisprudencia constitucional mediante la SCP 00237/2013 de 4 de enero, ha identificado que, en desmedro de la Ley de Deslinde Jurisdiccional, la jurisdicción indígena originaria campesina, tiene competencia para resolver los hechos y asuntos que tradicionalmente han resuelto y aquellos que considere pertinentes, sean estos de relevancia pública o no, pues no puede existir una reducción externa (legal) a los preceptos y valores fundamentales del Estado, en vigencia de la plurinacionalidad.

\section{Discusión}

\section{El Estado Plurinacional}

El art. 1 de la Constitución Política del Estado refiere que: "Bolivia se constituye en un Estado Unitario Social de Derecho Plurinacional Comunitario, libre, independiente, soberano, democrático, intercultural, descentralizado y con autonomías. Bolivia se funda en la pluralidad y el pluralismo político, económico, jurídico, cultural y lingüístico, dentro del proceso integrador del país.". Resalta en primera instancia, el término plurinacional que es abrazado desde el Preámbulo de la norma fundamental cuando se indica en lo pertinente que: "Dejamos en el pasado el Estado colonial, republicano y neoliberal. Asumimos el reto histórico de construir colectivamente el Estado Unitario Social de Derecho Plurinacional Comunitario". 
Tal circunstancia normativa implica que Bolivia giró no solo en su denominación, sino también la esencia del Estado mutó en lo que se identifica como Plurinacional. El estado plurinacional ya no implica una mera equivalencia con el Estado multiétnico y multicultural que asumió la reforma constitucional de 1994, sino que resulta en una completa visión y materialización de nueva de naturaleza, esencia y composición de la sociedad jurídica y políticamente organizada, donde se halla como eje motor, la pluralidad, no solo de culturas, sino de naciones.

Este razonamiento ha generado grandes elementos importantes. El Estado Plurinacional no implica únicamente la existencia de varias naciones dentro de un país, que coexisten y conviven en cohesión y participación estatal, sino la verdadera inclusión de las visiones, filosofías, usos y costumbres de las naciones, en particular de las naciones indígenas, en el entendimiento del quehacer público, jurídico, político, social, económico, cultural y axiológico (Sousa Santos, 2007, p.24). Para Yrigoyen (2011) la consolidación del Estado Plurinacional es un salto a favor en la lucha para la inclusión sustancial de los pueblos indígenas, a través de la institucionalización de nuevas formas de democracia participativa, el reconocimiento del autogobierno de los pueblos con sus propias instituciones y el cambio del paradigma político y económico que son ejes fundantes de los cambios constitucionales que trae consigo este modelo estatal (p. 141).

En ese entendido, se quiebra, de cierta forma, el paradigma tradicional del Estado-República, a efectos de dar lugar al modelo de lo comprendido por plurinacional, que es la consecuencia de un debate conceptual y práctico sobre la ontología estatal que recoge en sí dos elementos claves: El pluralismo jurídico, y político, y los principios y valores fundamentales de los pueblos indígenas.

El modelo plurinacional genera implicancias en todo ámbito. En el marco del reconocimiento de derechos, la categoría de pueblos indígenas ascienden a "naciones y pueblos indígenas originario campesinos", conforme a lo establecido en los arts. 2 y 30.1 de la Constitución Política del Estado (de ahora en adelante CPE), la oficialización de los idiomas nativos, conjuntamente con el castellano, la obligación de usar al menos dos de los mismos, en mérito a lo establecido en el art. 5, además de reconocer los valores indígenas para una sociedad plural, persiguiendo el vivir bien, los parámetros ama qhilla, ama llulla y ama sua ${ }^{1}$, en conformidad con lo dispuesto en el art. 8.I. También reconoce la existencia de las naciones y los pueblos indígenas originarios campesinos, a la luz de lo establecido en los arts. 2 y 30.1 de la citada norma fundamental, tales externos generan márgenes fuertes, al menos enunciativamente, para el fortalecimiento del pluralismo jurídico, puesto que en conjunción a la asimilación de los principios y valores fundamentales indígenas, se establece, en primera instancia, una línea de descolonización en el entendimiento jurídico-político del Estado, conforme a lo determinado en los arts. 9 y 98 de la CPE, situación robustecida por reconocer específicamente las funciones jurisdiccionales de estos grupos apuntados en los arts. 190, 191 y 192 del indicado cuerpo normativo.

1 No seas mentiroso, no seas flojo y no seas ladrón, traducción del quechua. 
Según Sousa-Santos (2007) el Estado Plurinacional obedece a una vocación descolonizadora, de transformación de instituciones, a efectos que estas vayan acorde a una visión plurinacional (p. 36), incluyendo el Tribunal Constitucional Plurinacional que tuvo que readecuarse al nuevo modelo de Estado, a efectos de garantizar la pluralidad y resguardar la vigencia de la igualdad jerárquica de las jurisdicciones, establecida en el art. 179.II de la CPE.

El plurinacionalismo se encuentra íntimamente ligado con el pluralismo jurídico, más, no son elementos equivalentes. El Estado Plurinacional se constituye porque lo nacional es diverso y no se constituye en una categoría social monocultural, la estructuración económica, social, jurídica y política reconoce y se erige a partir de todas las naciones y pueblos indígenas, originarios, campesinos y también la población intercultural del campo y la ciudad; asimismo, resguarda, brinda garantía y fomenta la identidad, el gobierno, el pluralismo jurídico y la integración intercultural de las naciones tanto del área rural como urbana, y por último, respeta la diversidad de formas de representación política (Rojas Tutela, 2011, p. 26).

La denominación plurinacional coadyuva a la profundización del pluralismo jurídico, comprendiendo que la aceptación de la convivencia de varias naciones en un mismo Estado, no solo se limita a una mera suma de las partes, sino que transforman el entendimiento estatal, en razón al reconocimiento de derechos las referidas categorías sociales, cuya naturaleza, en función al derecho a autogobernarse, a la luz de los arts. 2, 270 y 289 de la Constitución Política del Estado, implica la capacidad para que las naciones y pueblos indígena originario campesinos, tengan la capacidad de aplicar sus usos y costumbres a la hora de resolver disputas, controversias y litigios sometidos a su conocimiento a partir de los usos y costumbres de cada unidad social.

Asimismo, la jurisprudencia constitucional, a través de la Sentencia Constitucional Plurinacional (SCP de ahora en adelante) 1714/2012 de 1 de octubre, se refirió al momento fundacional del Estado Plurinacional, en el siguiente sentido literal: "El nacimiento del nuevo Estado boliviano a través de la aprobación de la Constitución Política del Estado el 25 de enero de 2009 y puesta en vigor el 7 de febrero del mismo año, caracteriza profundas transformaciones estructurales sustentadas en la plurinacionalidad, interculturalidad, pluralismo en sus diversas facetas, articuladas bajo un concepto de unidad en la pluralidad, como nuevos enfoques metodológicos y epistemológicos del manejo de la diversidad, pero fundamentalmente como procesos en construcción que confluyan en la materialización de un nuevo modelo de Estado compuesto: plurinacional, intercultural, comunitario con pluralismo político, económico, jurídico, cultural y lingüístico, que no se ha despojado de su carácter democrático, libre e independiente, ni escindido de su esencia de Estado de Constitucional de Derecho, erigiéndose por el contrario, con nuevas características organizacionales y territoriales: autonomías instituidas dentro del marco de la unidad del Estado y con estructuras plurales como el carácter comunitario, que realzan su aspecto diferenciador a las estructuras ya vividas, según proyecta la Constitución en su Preámbulo y en la norma contenida en su art. 1. Características que se encuentran cimentadas bajo el andamiaje de nuevos principios y valores supremos de carácter plural que deben converger de manera armónica y sinérgica". 
Tal precedente, hace alusión a la transformación profunda que el Estado boliviano ha experimentado mediante la implementación de la plurinacionalidad en la puesta en vigencia de la Constitución del 2009. Esto implica un cambio estructural y de percepción respecto a la pluralidad que funda el nuevo modelo de Estado, el cual también implica efectos plurales en la implementación de justicia, y dentro de ella, la aplicación de derecho penal.

Asimismo, la citada Sentencia Constitucional Plurinacional refiriéndose a la plurinacionalidad como eje fundacional, del Estado boliviano estableció, en lo pertinente, lo siguiente: "En tal sentido, el carácter del principio-valor de la plurinacionalidad, que deja en el pasado el 'Estado colonial, republicano y neoliberal' supone también el reconocimiento a los pueblos indígenas de su cualidad de nuevos actores que asumen el reto histórico de construir colectivamente el Estado Unitario Social de Derecho Plurinacional Comunitario, bajo la convergencia y conciliación de los principios y valores plurales, que deben ser irradiados en la conducción del nuevo destino del Estado Plurinacional que no es otro que el 'vivir bien' (suma qamaña) o la 'vida armoniosa' (ñandereko), y que se articulan bajo la interculturalidad reconocida por la Constitución (art. 1) como nueva forma de posicionamiento de la diversidad que reflejan los pueblos indígenas en los destinos de un país, y que obliga al Estado boliviano a reconocerse como Estado Plurinacional sostenido en los pueblos indígenas, que expresan diferencia y alteridad, quebrando así la invisibilidad y marginación a la que fueron sometidos desde la colonia, y proyectarse en la refundación del Estado, sobre la base de la descolonización, ideológica, política, económica y social, que construya un nuevo Estado unitario plurinacional comunitario, que exprese la confluencia de la diversidad étnico cultural del Estado Plurinacional en su unidad".

Por lo tanto, se entiende que desde la vigencia del Estado Plurinacional, el pluralismo jurídico se ha visto fortalecido, al menos enunciativamente, a partir de la igualdad jerárquica constitucional, mencionada anteriormente, circunstancia robustecida por el entendimiento de lo plurinacional en cuanto a la inclusión de los pueblos indígena originarios campesinos en agentes preponderantes del entendimiento constitucional, mediante la incorporación de sus visiones, filosofías, usos y costumbres al ethos constitucional de Bolivia.

\section{Propuesta}

En el marco de lo ya manifestado se pretende proporcionar, a través del presente trabajo una propuesta normativa, que albergue en sí la compatibilización constitucional entre la Ley de Deslinde Jurisdiccional y los valores y principios supremos constitucionales, los derechos indígenas y el orden fundamental plural. En ese mérito, se propone la promulgación del siguiente proyecto de ley: 


\section{LEY NO XXXX \\ LEY DE 4 DE FEBRERO DE 2021 \\ LUIS ARCE CATACORA \\ PRESIDENTE CONSTITUCIONAL DEL ESTADO PLURINACIONAL DE BOLIVIA}

Por cuanto, la Asamblea Legislativa Plurinacional ha sancionado la siguiente Ley:

\section{LA ASAMBLEA LEGISLATIVA PLURINACIONAL,}

\section{DECRETA:}

\section{LEY DE COMPATIBILIZACIÓN CONSTITUCIONAL DEL ÁMBITO MATERIAL PENAL PARA UN DESLINDE JURISDICCIONAL PLURAL}

ARTíCULO 1. (OBJETO). La presente Ley tiene por objeto la compatibilización constitucional de los principios, valores y disposiciones constitucionales y la Ley No 073 de 29 de diciembre de 2010, Ley de Deslinde Jurisdiccional.

ARTícUlO 2. Se modifica el art. 10.1 inc. a) del Capítulo III, de la Ley No 073 de 29 de diciembre de 2010, Ley de Deslinde Jurisdiccional, cuya disposición quedará redactada en el siguiente término:

"El ámbito de vigencia material de la jurisdicción indígena originaria campesina no alcanza a las siguientes materias:

a. En materia penal, los delitos contra el Derecho Internacional, los delitos por crímenes de lesa humanidad, los delitos contra la seguridad interna y externa del Estado, los delitos de terrorismo, los delitos tributarios, los delitos por corrupción cuando no generen efectos dentro de la descrita jurisdicción o cualquier otro delito cuya víctima sea el Estado, trata y tráfico de personas, tráfico de armas y delitos de narcotráfico. Los delitos cometidos en contra de la integridad corporal de niños, niñas y adolescentes, los delitos de violación, asesinato $u$ homicidio, debiendo considerarse que la justicia indígena conocerá todos los asuntos que tradicionalmente fueron resueltos conforme a sus usos y costumbres, salvo aquellos que obedezcan a un interés público imperioso, en el marco de lo descrito en los tratados internacionales, Constitución Política del Estado y en la presente Ley.

\section{DISPOSICIÓN FINAL}

ÚNICA. La presente Ley se traducirá, publicará en todos los idiomas de las naciones y pueblos indígena originario campesinos del Estado Plurinacional de Bolivia. 


\section{DISPOSICIÓN DEROGATORIA Y ABROGATORIA}

ÚNICA. Quedan derogadas y abrogadas todas las disposiciones jurídicas contrarias a la presente Ley.

Remítase al Órgano Ejecutivo, para fines constitucionales.

Es dada en la Sala de Sesiones de la Asamblea Legislativa Plurinacional, a los cuatro días del mes de febrero del año dos mil veintiuno."

CONCLUSIONES

La compatibilización debe entenderse dentro del margen del resguardo a los derechos fundamentales, a los instrumentos internacionales y al bloque de constitucionalidad, porque si bien, en el marco de una compatibilización constitucional, el ámbito de vigencia material de la jurisdicción indígena originaria campesina no debe limitarse a lo dispuesto en la Ley de Deslinde Jurisdicción, en aplicación directa de la Constitución Política del Estado, aun cuando la jurisprudencia constitucional reconozca que los pueblos y naciones indígenas son competentes para conocer todos los actos, hechos y conflictos que histórica y tradicionalmente conocieron, la sustanciación de cada uno de los asuntos sometidos a su conocimiento deben respetar los Derechos Humanos y la interpretación de ellos.

\section{REFERENCIAS}

Alexy, R. (2008).La fórmula del peso. EnM.Carbonell (Ed.), El Principio de Proporcionalidad y su Interpretaciòn Constitucional. Ministerio de Justicia y Derechos Humanos.Cocarico, E. (2006). El etnocentrismo político-jurídico y el estado multinacional: Nuevos desafíos para la democracia en Bolivia. América Latina Hoy, 43, 131-152

de Bolivia, E. P. (2009). Constitución política del estado. Gaceta Oficial del Estado Plurinacional de Bolivia, 7

Rojas Tutela, F. (2011). Del monismo al pluralismo jurídico: Interculturalidad en el Estado Constitucional. En E. Cóndor (Ed.), Los Derechos Individuales y los Derechos Colectivos en la Construcción del Plurarlismo Jurídico en América Latina. Fundación Konrad Adenauer Stiftung

Sousa Santos, B. (2007). La Reinvención del Estado y El Estado Plurinacional. En Pensar el Estado y la sociedad: Desafíos actuales. Consejo Latinoamericano de Ciencias Sociales
Sousa Santos, B. (2012). Cuando los excluidostienen Derecho: Justicia indígena, plurinacionalidad e interculturalidad. En Justicia indígena, plurinacionalidad e interculturalidad en Bolivia (pp. 11-48). Abyala

Walsh, C. (2009). El Estado Plurinacional e Intercultural. En Plurinacionalidad, democracia en a diversidad (Abya-Yala)

Yrigoyen, R. (2011). El horizonte del constitucionalismo pluralista. En C. Rodríguez (Ed.), Derecho en América Latina. Un mapa para el pensamiento jurídico del siglo XXI. Siglo XXI

Zagrebelsky, G. (1995). El derecho dúctil: Ley, derechos, justicia. Editorial Trotta : Comunidad de Madrid, Consejería de Educación y Cultura 